\title{
Where Are the New Cough Treatments: A Debriefing of Recent Clinical Proof-of-Concept Trials with the NOP Agonist SCH 486757
}

\author{
Robbie L. McLeod ${ }^{\mathrm{a}}$ Deen B. Tulshian ${ }^{\mathrm{b}}$ Jonathan Sadeh ${ }^{\mathrm{c}}$ \\ ${ }^{a}$ Bone, Respiratory, Immunology and Dermatology, ${ }^{b}$ Chemistry and ${ }^{\mathrm{C} C l i n i c a l}$ Research, Merck Research Laboratories, \\ Kenilworth, N.J., USA
}

\section{Key Words}

Cough treatment $\cdot$ Nociceptin/orphanin FQ peptide

agonist $\cdot$ SCH 486757

\begin{abstract}
Cough continues to be one of the top reasons why patients seek medical attention from health care providers. The prescription antitussive market is dominated by opioids, such as codeine that produces inconsistent efficacy and is often accompanied by significant side effect liabilities. Consequently, cough represents an unmet medical need and an underserved market. Yet, against the backdrop of increasing cough research, the development of novel treatments has been exceptionally challenging with dextromethorphan being the last US drug approved for cough almost a half century ago. We support the position that an unambiguous and actionable 'road map' that clearly delineates the pathway forward for new cough suppressants from basic research to and beyond clinical proof-of-concept studies will be an important aspect for future success of this pharmacological class of drug. Pivotal to the establishment of such a road map will be the review of lessons learned from antitussive agents that have been recently progressed to proof-of-concept trials. In the present commentary, we briefly discuss observations and challenges pertaining to $\mathrm{SCH} 486757$, a selective orally active NOP agonist that has recently advanced to human antitussive testing.

Copyright $\odot 2011$ S. Karger AG, Basel
\end{abstract}

\section{Background}

No new antitussive agent has reached the US clinical market since the launch of dextromethorphan over 50 years ago. Industry, with few exceptions, has been reluctant to invest significant resources into this area, perceiving it to be an area of low unmet medical need. However, cough continues to top the list as one the most symptomatic complaints causing patients to seek medical attention from a health care provider $[1,2]$. Presently, antitussive treatment options are limited, although pharmacy shelves are filled with over-the-counter products which make up a myriad of 'cough and cold' products that have dubious or inconsistent efficacies. Moreover, the safety of some cough suppressants has been brought into the spotlight. Recently the Food and Drug Administration has recommended that children 2 years old and younger should not be given over-the-counter cough and cold products due to the possibility of serious life-threatening adverse events, including convulsions, rapid heart rate and decreased levels of consciousness [3-5]. Opioids, such as codeine, are effective antitussive drugs but their perceived standing as the 'gold standard' is currently being debated in the research community [6]. Moreover, opioids have significant liabilities (i.e. addiction potential, gastrointestinal constipation, respiratory depression, etc.) that may limit their use as a cough suppressant.

\section{KARGER}

Fax +41613061234 E-Mail karger@karger.ch www.karger.com
Robbie L. McLeod, PhD

Merck Research Laboratories - Bone, Respiratory, Immunology and Dermatology 2015 Galloping Hill Road

Kenilworth, NJ 07033-0539 (USA)

Tel. +1 908740 3286, E-Mail robbie.mcleod@ spcorp.com 
There is a significant level of scientific activity occurring in the cough arena. A cursory search of the term 'cough' in the Pubmed database yields over 2,000 references in the last 2 years alone. It is without question that we have substantially increased our understanding of cough since the very early ground-breaking work by Widdicombe [7] and May and Widdicombe [8]. Work at the basic science level has engendered the identification of potentially novel attractive targets for the treatment of cough [9-12]. Medicinal chemists have synthesized and optimized small molecules that selectively interact at these targets. However, few of these drugs have made it to clinical proof-of-concept testing, and none (that we know of) have demonstrated a convincing level of cough suppression to ultimately become a marketed product. Thus, there is a vital question that rises from the cauldrons of frustration: is it possible to develop a new cough suppressant? We would argue, yes. The industry is just beginning to define a 'road map' for the development of drugs [13]. However, we would temper our position by acknowledging the limitations and challenges that are associated with progression of novel antitussive agents from animal models to clinical proof-of-concept studies and regulatory approval. Building upon past experiences with clear examples of agents that have advanced through industry pipelines will be critical in forging the aforementioned road map. In this commentary, we provide insights into our nociceptin/orphanin FQ peptide (NOP) receptor agonist cough program, to which SCH 486757 was recently advanced through 2 clinical studies.

\section{Chemistry}

SCH 486757, named as 8-[bis(2-chlorophenyl)methyl]3-(2-pyrimidinyl)-8-azabicyclo[3.2.1.]octan-3-ol, was identified after extensive structure-activity relationship investigation of a lead from the high throughput screening of Schering Plough file compounds. The key pharmacophores in SCH 486757 which are responsible for its superior biological and physical profiles are a pyrimidine at the $\mathrm{C}-3$ carbon, an ethylene bridge between the $\mathrm{C}-1$ and C-5 carbons and a benzhydryl moiety at the tropane nitrogen. SCH 486757 (free base) has no stereogenic centers (i.e. no enantiomers), and the free base exists as a white crystalline material (melting point: $168^{\circ} \mathrm{C}$ ) with a molecular weight of 440 .

\section{Preclinical Perspective of SCH 486757 in Animal Models of Cough}

In 1994 a new G-protein-coupled orphan receptor was identified from a human cDNA library [14]. This NOP receptor shared significant homology with classical opioids but maintained some pharmacological distinctions. For example, opioid peptides do not display significant affinity for NOP receptors, and nociceptin/orphanin FQ (the endogenous ligand for NOP) does not simulate classical opioid receptors. In 2001 we administered nociceptin/orphanin FQ, central and peripherally, to guinea pigs and found that the peptide attenuated cough elicited by aerosolized capsaicin to the airways [15]. Our work was confirmed by Lee et al. [16], who found that nociceptin/orphanin FQ suppressed cough in an acid-evoked cough model. In addition to inhibiting chemical irritantprovoked cough in guinea pigs, nociceptin/orphanin FQ blocks cough produced by mechanical perturbation of the trachea in the cat [17]. Follow-up experiments with various nonpeptide NOP agonists supported the position that this pharmacological class of drug suppresses cough in animal models [18-21].

The preclinical profile of SCH 486757 has been described by McLeod et al. [22]. In brief, SCH 486757 binds human NOP receptor with a $\mathrm{K}_{\mathrm{i}}$ value of $4.6 \mathrm{nmol} / \mathrm{l}$. The drug displays a 211-, 178- and 3,206-fold selectivity for NOP over MOP, KOP and DOP opioid receptors. SCH 486757 is orally absorbed, well tolerated with no substantial safety issues and displays a good overall pharmacokinetic profile in the guinea pig, rat and dog [22]. In the guinea pig capsaicin cough model, SCH 486757 at oral dose levels between 0.01 and 0.3 , suppressed cough (specifically by NOP activation) equivalent to opioids like codeine and hydrocodone. In the feline mechanically evoked cough model, SCH 486757 diminishes cough and expiratory abdominal electromyogram amplitude (a surrogate measure for cough intensity). Thus, given the favorable antitussive profile of $\mathrm{SCH} 486757$ in preclinical animal models, the drug was advanced to proof-of-concept studies in humans.

\section{Clinical Observations}

Two phase Ib/II SCH studies have been conducted with SCH 486757. The data was presented at the 2 nd American Cough Symposium in June 2009 (New Jersey, USA). A manuscript detailing the results of SCH 486757 in subacute cough patients has recently been published 


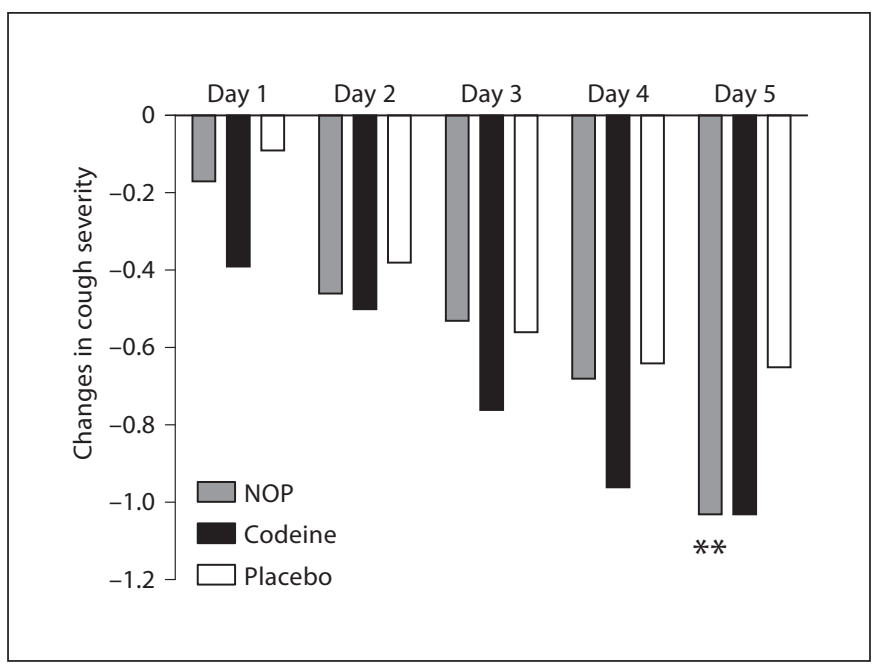

Fig. 1. Changes from baseline in subjective cough severity during a 5-day treatment period with SCH 486757 (NOP $100 \mathrm{mg}$ b.i.d.), codeine $\left(30 \mathrm{mg}\right.$ b.i.d.) and placebo. ${ }^{* *} \mathrm{p}<0.1$, compared to placebo.

[23]. Results from a second study in chronic idiopathic cough are forthcoming. P03069 was a double-blind, parallel-group, crossover study, examining the antitussive activity of SCH 486757 (100 mg b.i.d.), codeine (30 mg b.i.d.) and placebo, in patients with persistent postviral cough. Highlights from P03069 are shown in figures 1 and 2. In brief, the study showed that SCH 486757 reduced subjective cough scores as much as codeine, although this did not achieve statistical significance. The drug also reduced cough counts on days 1 and 5 significantly more than placebo.

\section{Challenges for the Development of Novel Antitussive Drugs and the Way Forward}

It is well recognized that respiratory inflammation during disease states may produce significant changes in pulmonary sensory nerve excitability and alter cough responses [24-26]. Unfortunately, current experimental challenge cough models that comprise the employment of healthy animals do not capture all tussigenic aspects that may be important in human disease cough. Indeed, it is clear that the capsaicin irritant guinea pig cough model overpredicted the efficacy of SCH 486757 in the current clinical studies. Then, should we get rid of experimental provocation models? A report by Canning

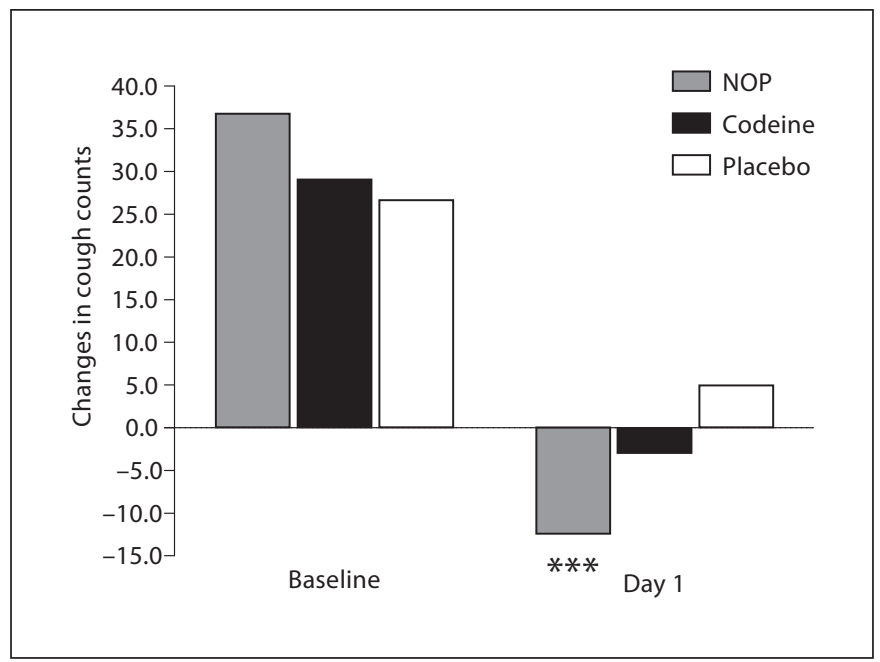

Fig. 2. Antitussive effect of orally administered SCH 486757 (NOP $100 \mathrm{mg}$ b.i.d.) and codeine (30 mg b.i.d.) in patients with persistent postviral cough. The figure shows the change (from baseline) in cough frequency (determined by Lifeshirt ${ }^{\mathrm{TM}}$ ) on day 1 of a 5 -day dosing regimen. ${ }^{* *} \mathrm{p}<0.05$ compared to placebo.

[27] eloquently describes the advantages and disadvantages of studying cough in animals. One commonly provided rationale for the use of provocation animal models is that therapeutic agents that suppress cough in humans display antitussive activities in the animals. We would also suggest that the rapid throughput of the guinea pig capsaicin model allowed optimization and a rationale selection of SCH 486757 based on comparative potencies and efficacies relative to other NOP agonists and standard antitussive drugs. Results from the guinea pig capsaicin cough model suggested that maximum antitussive effects of SCH 486757 and codeine were comparable. Interestingly, in the human acute cough study, SCH 486757 and codeine produced equivalent antitussive effects. The guinea pig cough model aided in defining the antitussive mechanism of action of SCH 486757 [22]. Specifically, we found that the cough-suppressing effect of SCH 486757 was blocked by a selective NOP antagonist but not by a classical opioid antagonist. With all of this being said, a careful reexamination of established animal models with a subsequent development of newer models that encapsulate greater aspects of human disease cough is clearly merited. For example, human pulmonary sensory nerve excitability resulting from subchronic or chronic exposure to a myriad of inflammatory cells, chemokines, cytokines and mediators is an important aspect of cough that is not represented in animal models that rely solely 
on irritant or mechanical airway provocations to elicit cough. There have been some efforts in the scientific community to develop 'exacerbated cough' animal models in which tussive activity is determined by challenge agents such as critic acid or capsaicin following $\mathrm{SO}_{2}$ or cigarette smoke [28]. In 2009, we published a study on an infectious tracheobronchitis canine model of cough with the goal of utilizing it as a disease model to access novel antitussive drugs [21]. These approaches to the preclinical pharmacological study of cough are a step in the right direction (compared to historical cough models) but unfortunately they are not fully characterized, not standardized across different laboratories and their correlation with human cough is not fully understood.

Studies in the clinic proved challenging as well, from a design and end point perspective. Since the largest number of patients present with acute cough after an upper respiratory infection, and since substantial resources are spent on caring for these patients (e.g. doctor visits, over-the-counter medications), developing and studying new antitussives in this setting is an appropriate approach. This patient population has proven to be very challenging since patients recover within a few short days with no intervention; thus, showing an improvement over placebo would be very difficult with a high placebo effect. End points are also difficult to measure - subjective assessment of cough severity is difficult when symptoms are improving rapidly. Cough counting has been suggested as an objective end point, and several investigational devices have been developed. Although counting may ultimately provide some objective parameter for use in drug development and the field has progressed in the past few years, there is still no agreement on how to measure and how to count coughs, and no gold standard has been established. Furthermore some studies have shown a weak correlation between changes in cough counts and symptoms, as was the case in our studies. Although this is not a consistent finding, it is fair to say that cough counting or other objective measures alone do not give an accurate assessment of the response to antitussive therapy.

To solve the problem of a rapidly changing cough, as is seen in the acute model, some have suggested looking at a chronic idiopathic cough model. These are patients experiencing a severe dry cough for over 3 months, often starting after an acute upper respiratory tract infection. With new referral centers for patients with chronic cough opening around the world, we are also discovering the problem may be more common than previously reported [29]. We conducted a placebo-controlled, randomized, crossover study of NOP in a group of patients with chronic idiopathic cough and will present our data soon. Clearly this population offers an 'enriched population' of patients with very severe disease where we are more likely to pick up a small signal in efficacy. Since they have been experiencing a severe cough for so long, the placebo effect, a significant problem in all antitussive studies, is also very low [29]. Unfortunately we do not believe this is an appropriate model for future drug development either the number of patients is still small and only few centers around the world have access to them, making large studies very difficult to conduct. The etiology of the cough is likely multifactorial, including infectious, reflux and various other etiologies. Showing efficacy in this model may not translate into efficacy in an acute postinfectious cough model, and showing efficacy in that population may be needed before the drug is used in that patient population. Therefore we believe that although chronic idiopathic cough is an important medical problem, it is not a good proof-of-concept model for new antitussive drugs.

A subacute cough model has also been suggested as an appropriate setting to test a new antitussive. In this model we study patients after the acute upper respiratory tract infection has resolved but while they are still experiencing a bothersome, usually dry cough. Woodcock et al. [23] recently presented data from a study of SCH 486757 in patients with subacute cough (here defined as cough for more than 2 weeks but less than 3 months). We evaluated the drug against placebo and codeine as an active control, using end points of subjective cough severity and cough counts. With 91 patients randomized into this study, we were able to show strong trends in reduction of both subjective and objective cough measures in a 5-day treatment period. Enrollment was difficult and was cut short before the anticipated 150 subjects were randomized. Although we believe this is the first report of significant cough suppression in a clinical trial, treatment with this drug was also associated with significant sedation, which limits its use. While there were many challenges in conducting this study, we believe this is likely the most appropriate model to test new antitussive agents early in their development. Although recruitment may be difficult, the patients are seen in high numbers at primary care doctors' offices, and the etiology of their cough is likely closely linked to one etiology, postinfectious. The rate of improvement in cough severity slows down after 2 weeks, making it easier to detect a drug effect and decreasing the potential placebo effect. 


\section{Conclusions}

Developing novel antitussive agents is a challenging endeavor with significant obstacles. From the preclinical development perspective, current animal models (i.e. guinea pig irritant models) appear not to be fully predictive of clinical efficacy but these models do have value in the lead optimization process. However, it is recognized by the research community that the development of novel 'disease' models with greater translatability to human cough will be of significant value to antitussive drug discovery paradigms. From the clinical perspective, we sug- gest initial proof-of-concept studies be conducted in subacute cough patients (i.e. cough symptoms greater than $2-3$ weeks but less than $8-12$ weeks). The use of validated 24-hour cough monitoring systems that determine objective measures, which can be correlated with subjective end points, is a critical aspect of establishing proof of concept. Finally, although clinical results with opioids such as codeine are variable, this pharmacological class remains the comparator by which all novel antitussive agent will be benchmarked against and thus should be used as a comparator in clinical studies.

\section{References}

1 Cherry DK, Woodwell DA: National ambulatory medical care survey 2000 summary. Adv Data 2002;328:1-32.

2 Morice AH: Epidemiology of chronic cough. Eur Respir Rev 2002;85:222-225.

3 Rimsza ME, Newberry S: Unexpected infant deaths associated with use of cough and cold medications. Pediatrics 2008; 122:e318e322.

4 Kuehn BM: Citing serious risks, FDA recommends no cold and cough medicines for in fants. JAMA 2008;299:887-888.

5 Schaefer MK, Shehab N, Cohen AL, Budnitz DS: Adverse events from cough and cold medications in children. Pediatrics 2008; 121:783-787.

6 Bolser DC, Davenport PW: Codeine and cough: an ineffective gold standard. Curr Opin Allergy Clin Immunol 2007;7:32-36.

7 Widdicombe JG: Receptors in the trachea and bronchi of the cat. J Physiol Lond 1954; 123:71-104

8 May AJ, Widdicombe JG: Depression of the cough reflex by pentobarbitone and some opium derivatives. Br J Pharmacol Chemother 1954;9:335-340

-9 McLeod RL, Tulshian DB, Hey JA: Novel pharmacological targets and potential progression of new antitussive drugs. Expert Opin Ther Patents 2003;13:1501-1512.

10 Chung KF: Drugs to suppress cough. Expert Opin Investig Drugs 2005;14:19-27.

11 Belvisi MG: Preclinical assessment of novel therapeutics on the cough reflex: cannabinoid agonists as potential antitussives. Lung 2008; 186:S66-S69.

12 Carr MJ: Antitussives: the pharmacological pipeline. Pulm Pharmacol Ther 2009;22: 152-154.

13 Birring SS: Developing antitussives: the ideal clinical trial. Pulm Pharmacol Ther 2009;22: 155-158.

14 Mollereau C, Parmentier M, Mailleux P, Butour JL, Moisand C, Chalon P, Caput D, Vas- sart G, Meunier JC: ORL1, a novel member of the opioid receptor family - cloning, functional expression and localization. FEBS Lett 1994;341:33-38.

15 McLeod RL, Parra LE, Mutter JC, Erickson $\mathrm{CH}$, Carey GJ, Tulshian DB, Fawzi AB, Smith-Torhan A, Egan RW, Cuss FM, Hey JA: Nociceptin inhibits cough in the guineapig by activation of ORL(1) receptors. Br J Pharmacol 2001;132:1175-1178.

16 Lee MG, Undem BJ, Brown C, Carr MJ: Effect of nociceptin in acid-evoked cough and airway sensory nerve activation in guinea pigs. Am J Respir Crit Care Med 2006;173: 271-275.

-17 Bolser BC, McLeod RL, Tulshian DB, Hey JA: Antitussive action of nociceptin in the cat. Eur J Pharmacol 2001;430:107-111.

$\checkmark 18$ Ho GD, Anthes J, Bercovici A, Caldwell JP, Cheng KC, Cui X, Fawzi A, Fernandez X, Greenlee WJ, Hey JA, Korfmacher W, Lu SX, McLeod RL, Ng F, Smith-Torhan A, Tan Z, Tulshian D, Varty GB, Xu L, Zhang H: The discovery of tropane derivatives as nociceptin receptor ligands for the management of cough and anxiety. Bioorgan Med Chem Lett 2009;19:2519-2523.

19 Yang S-W, Ho G, Tulshian DB, Greenlee WJ, Tan Z, Zhang H, Fawzi A, Anthes J, Varty G, Fernandez X, McLeod RL, Hey JA: Identification of 3-substituted N-benzhydryl-nortropane analogs as nociceptin receptor ligands for the management of cough and anxiety. Bioorgan Med Chem Lett 2009;19: 2482-2486.

20 McLeod RL, Jia Y, Fernandez X, Parra LE Wang X, Tulshian DB, Fawzi AB, SmithTorhan A, Hey JA: Antitussive profile of the NOP agonist Ro64-6198 in the guinea pig. Pharmacology 2004;71:143-149.

21 McLeod RL, Tulshian DB, Ho GD, Bolser DC, Jayappa H, Fernandez X, Parra LE, Zimmer JC, Erickson CH, Fawzi AB, Craig Lehr C, Erskine J, Smith-Torhan A, Zhang H, Hey
JA: Effect of a novel NOP receptor agonist (SCH 225288) on guinea pig irritant-evoked, feline mechanically induced and canine infectious tracheobronchitis cough. Pharmacology 2009;84:153-161.

22 McLeod RL, Tulshian DB, Baptista M, Bolser DC, Ho GD, Korfmacher W, Xu X, Veals J, Wainhaus, Fernandez X, Parra LE, Zimmer JC, Erickson CH, Fawzi AB, Smith-Torphan A, Hey JA: Pharmacological profile of the NOP agonist and cough suppressing agent SCH 486757 [8-(bis[2-chlorophenyl] methyl)-3-(2-pyrimidinyl)-8-azabicyclo(3.2.1.)octan-3-ol]. Eur J Pharmacol 2010; 630:112-120.

23 Woodcock A, McLeod RL, Sadeh J, Smith JA: The efficacy of a NOP1 agonist (SCH 486757) in subacute cough. Lung 2010;188(suppl 1):S47-S52.

24 Choudry NB, Fuller RW, Pride NB: Sensitivity of the human cough reflex: effect of inflammatory mediators prostaglandin $\mathrm{E}_{2}$, bradykinin, and histamine. Am Rev Respir Dis 1989;140:137-141.

25 Riccio MM, Proud D, Undem BJ: Enhancement of afferent nerve excitability in the airways by allergic inflammation. Pulm Pharmacol 1995;8:181-185.

26 Carr MJ, Undem BJ: Inflammation-induced plasticity of the afferent innervation of the airways. Environ Health Perspect 2001;109: 567-571.

27 Canning BJ: The cough reflex in animals: relevance to human cough research. Lung 2008; 186:S23-S28.

28 Lewis CA, Ambrose C, Banner K, Battram C, Butler K, Giddings J, Mok J, Nasra J, Winny C, Poll C: Animal models of cough: literature review and presentation of a novel cigarette smoke-enhanced cough model in the guinea-pig. Pulm Pharmacol Ther 2007;20:325333.

29 Morice AH: Chronic cough: epidemiology. Chron Respir Dis 2008;5:43-47. 